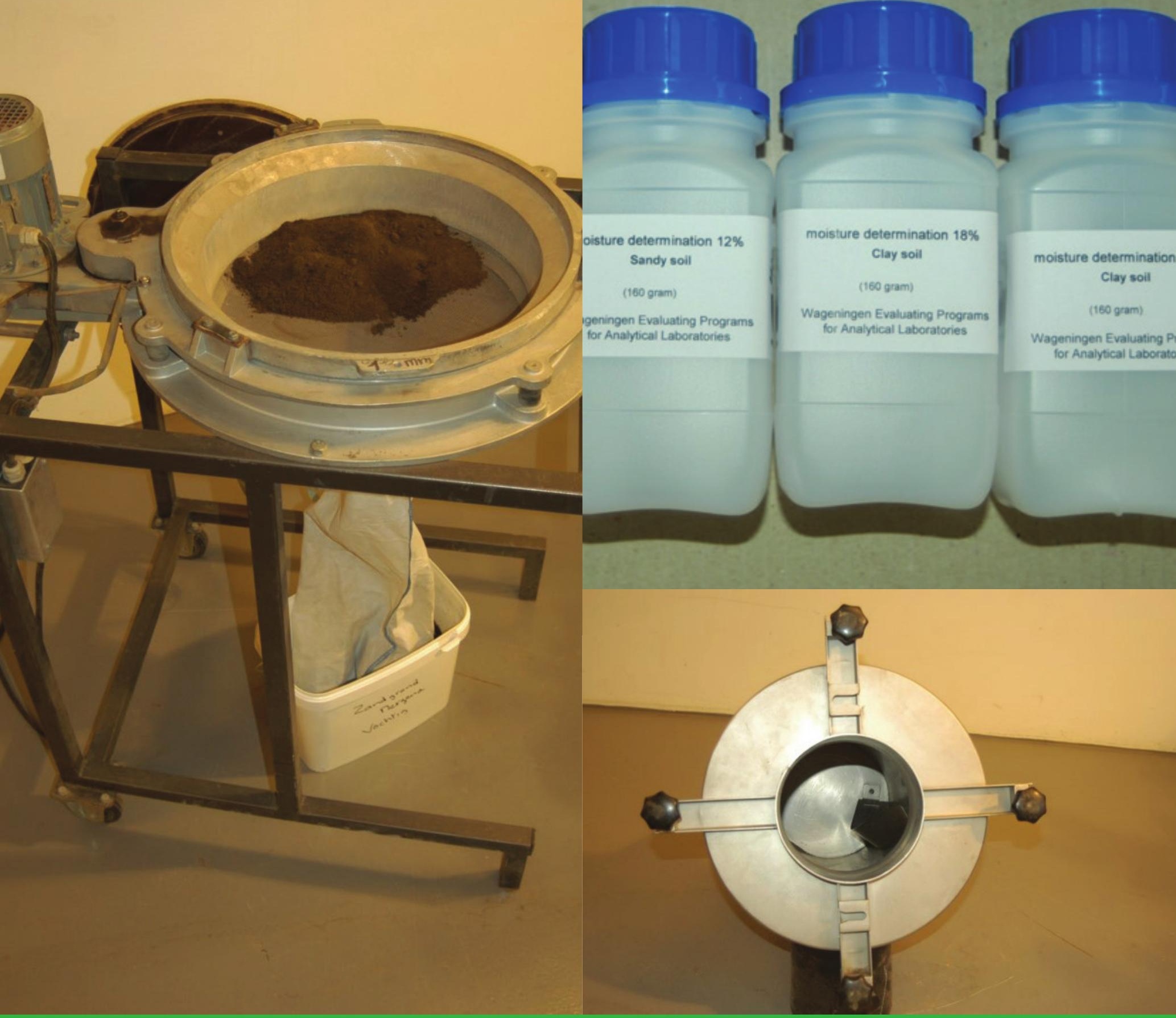

Validation of ISO/DIS 20244 Soil quality - Screening method for water content Determination by refractometry

Winnie van Vark, Peter Pellen, Steven Crum and Joop Harmsen 



\section{Validation of ISO/DIS 20244 Soil quality - Screening method for water content - Determination by refractometry}

Winnie van Vark $^{1,2}$, Peter Pellen ${ }^{1}$, Steven Crum $^{1,3}$ and Joop Harmsen ${ }^{3,1}$

1 WEPAL/QUASIMEME

2 Wageningen University

3 Wageningen Environmental Research 
Winnie van Vark, Peter Pellen, Steven Crum and Joop Harmsen, 2018. Validation of ISO/DIS 20244 Soil quality - Screening method for water content - Determination by refractometry. Wageningen, Wageningen Environmental Research, Report 2911. 26 pp.; 3 fig.; 7 tab.; 5 ref.

ISO/TC190/Soil Quality has developed a standard to enable measurement of water content in soil and soil-like materials using a screening method ISO/DIS 20244.

To become a full standard, the screening method required validation to show the applicability and comparability of the method in different laboratories (repeatability and reproducibility). This validation was organised by WEPAL, (Wageningen Evaluating Programs for Analytical Laboratories), which is part of Wageningen University in the Netherlands. 11 laboratories participated in the validation. Samples with comparable and known water content were distributed. Repeatability and reproducibility were calculated according ISO 5725. The measured water contents were lower than measured with ISO 11465. Probably the sucrose solution is not able to extract all water. Correction of the result using clay content and or organic matter content may be possible, but needs further investigation. The responsible ISO Working Group has to decide if and how the results can be added to ISO/DIS 20244 to become a full standard.

Keywords: validation, soil, water content, standard, ISO, screening.

The pdf file is free of charge and can be downloaded at https://doi.org/10.18174/463819 or via the website www.wur.nl/environmental-research (scroll down to Publications - Wageningen Environmental Research reports). Wageningen Environmental Research does not deliver printed versions of the Wageningen Environmental Research reports.

2018 Wageningen Environmental Research (an institute under the auspices of the Stichting Wageningen Research), P.O. Box 47, 6700 AA Wageningen, The Netherlands, $\mathrm{T}+31$ (0)317 4807 00, www.wur.nl/environmental-research. Wageningen Environmental Research is part of Wageningen University \& Research.

- Acquisition, duplication and transmission of this publication is permitted with clear acknowledgement of the source.

- Acquisition, duplication and transmission is not permitted for commercial purposes and/or monetary gain.

- Acquisition, duplication and transmission is not permitted of any parts of this publication for which the copyrights clearly rest with other parties and/or are reserved.

Wageningen Environmental Research assumes no liability for any losses resulting from the use of the research results or recommendations in this report.

Wageningen Environmental Research Report 2911 | ISSN 1566-7197

Photo cover: Peter Pellen 


\section{Contents}

$\begin{array}{ll}\text { Summary } & 5\end{array}$

1

$\begin{array}{ll}\text { Introduction } & 7\end{array}$

2

$\begin{array}{lr}\text { Method } & 8\end{array}$

$\begin{array}{lll}2.1 & \text { WEPAL } & 8\end{array}$

2.2 Principle of ISO/CD $20244 \quad 8$

2.3 Preparation of the sample $\quad 8$

$\begin{array}{ll}2.4 & \text { Measurement of water content } \\ 2.5 & 10\end{array}$

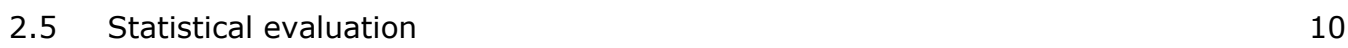

2.5.1 ISO 5725 model 10

2.5.2 WEPAL model 11

3

$\begin{array}{ll}\text { Results and discussion } & 12\end{array}$

3.1 Stability and homogeneity of the samples 12

3.1.1 Homogeneity 12

3.1.2 Stability of the stored samples 13

3.1.3 Stability of sample after opening of the bottle 14

$\begin{array}{lll}3.2 & \text { Conclusions for the samples prepared } & 14\end{array}$

$\begin{array}{ll}3.3 & \text { Experiences of the laboratories } \\ 3.4 & 15\end{array}$

3.4 Statistical evaluation according ISO 5725

3.5 Trueness 16

$\begin{array}{lll}3.6 & \text { Effect of soil properties } & 17\end{array}$

$\begin{array}{lll}3.7 & \text { Statistical evaluation according the WEPAL model. } & 17\end{array}$

$\begin{array}{ll}\text { References } & 21\end{array}$

Annex 1 Excel sheet used by the participants to deliver the results 22

$\begin{array}{lll}\text { Annex } 2 & \text { Results of individual laboratories } & 23\end{array}$ 



\section{Summary}

ISO/TC190/Soil Quality has developed an international standard to enable measurement of the water content in soil and soil-like materials using a screening method. The standard ${ }^{1}$ 'ISO/DIS 20244 Soil quality-- Screening method for water content - Determination by refractometry' describes the extraction of the soil using a sucrose solution to be followed by measurement. To become a full standard, the method requires validation to demonstrate the repeatability and reproducibility of the method. This validation was organised by WEPAL (the Wageningen Evaluating Programmes for Analytical Laboratories organisation), which is part of Wageningen University in the Netherlands.

11 laboratories participated in the validation. Four soil samples were selected with different soil properties and prepared with different water contents. Before the validation, WEPAL has tested the stability and homogeneity of the samples and all samples were judged suitable for the validation.

The statistical test for the validation was carried out according to the ISO 5725 Series. Outliers were identified using the Cochran's test and Grubbs' test described in ISO 5725-2. The statistical system of WEPAL (NDA, Normal Distribution Assumption) was also used to evaluate the data. It is up to the responsible ISO working group to decide if the repeatability and reproducibility calculated according ISO 5725 are sufficient for this screening technique.

ISO/DIS 20244 is a screening method designed to give a quick estimate of the water content, which is normally measured using the more time consuming method ISO 11465 (drying the sample at $105^{\circ} \mathrm{C}$ ). Having results of both methods made it possible to report the trueness of the results of ISO/DIS 20244. It is shown that ISO/DIS 20244 gives lower results than ISO 11465. Taking into account the results of all samples, the results are relatively $27 \%$ lower. If only the two sand samples are considered, the results are better comparable, but still $13 \%$ too low. The two clay samples were of the same origin but having different water content. Results of the clay samples were absolutely $5.5 \%$ too low (13.4 and $9.5 \%$ instead of 18.9 and $14.9 \%$ ). It can be concluded that the sucrose solution is not able to extract the same amount of water as is removed with drying the samples at $105^{\circ} \mathrm{C}$.

The difference between ISO 11465 and ISO 20244 correlates with both clay content and organic matter content. It is recommended to investigate this more intensively with a large number of samples. This may yield a correction factor based on the general soil properties clay and organic matter content. The ISO working group responsible for this standard has to decide if such an action is necessary.

\footnotetext{
${ }^{1}$ In order to improve the traceability of this report we used as title for the standard 'ISO/DIS 20244 Soil quality-An on-site test method to quickly determine water contents in soil by refractometry' as decided in the ISO/TC190 meeting of 2018 in Seoul. Before this meeting, the title 'ISO/DIS 20244 Soil quality-An on-site test method to quickly determine water contents in soil by refractometry' was used.
} 


\section{Introduction}

As described in ISO/DIS 20244, On-site determination of water contents has advantages in geotechnical engineering, agriculture, environmental- and climate studies. One applications of water content tests is for global environmental protection work. Management of water in soil to e.g. control greenhouse gas emission is important, because water content strongly influences the emissions of $\mathrm{N}_{2} \mathrm{O}$. With this background, a quick check of soil for water contents has gained interest especially for studies at regional and national scale where many samples need to be analysed. In such studies screening technologies are desired which can provide results directly at the site.

In laboratories, water contents are determined by weighing soil samples before and after drying at $105^{\circ} \mathrm{C}$, but this method cannot be applied in the field. If this method is used, soil samples shall be transported from the site to a laboratory and meanwhile the water content in the soil sample should be kept constant. On-site screening of the water content in soil requires another principle of measurement. Solvent extraction of water from soil followed by refractive index measurement is expected to be suitable to such situations as it provides an immediate result at the site.

This International Standard ISO/DIS 20244 specifies a method for rapid on-site determination of water contents. The method is based on refractive index measurement of a sucrose solution after mixing with the soil sample. The output by the instrument is indicated either as refractive index or as sugar content (e.g. Brix degrees). Both data can be simply converted to the amount of water in the sample by using a calibration curve. The method is rapid, simple, and inexpensive and can be applied in the field to provide a water content in a few minutes.

'ISO/DIS 20244: Soil quality - - Screening method for water content - Determination by refractometry' became available in 2016 and has to be validated to become a full ISO standard. WEPAL, part of Wageningen University, has been asked to organize this validation and the results of the validation are described in this report. 


\section{Method}

\section{$2.1 \quad$ WEPAL}

WEPAL (Wageningen Evaluating Programmes for Analytical Laboratories) is part of Wageningen University in the Netherlands. It organises five large, international, laboratory-evaluating programmes for environmental- and agricultural laboratories. For more information, please visit www.wepal.nl. WEPAL organised the validation presented in this report, including the selection, preparation and distribution of samples, instructions for participation and the statistical evaluation.

\subsection{Principle of ISO/CD 20244}

The International Standard ISO/DIS 20244 specifies a method for rapid on-site determination of water contents. The method is based on refractive index measurement of a sucrose solution after mixing with the soil sample. The output by the instrument is indicated either as refractive index or as sugar content (e.g. Brix degrees). Both data can be simply converted to the amount of water in the sample by using a calibration curve based on the sucrose solution with different amounts of water.

The method is rapid, simple, and inexpensive and not significantly influenced by soil matrices and can be applied in the field to give already a water content in several minutes.

\subsection{Preparation of the sample}

In most methods and laboratory evaluating programs, dry samples are distributed. This kind of samples are homogenized in order to send samples with comparable properties to the different laboratories. For this validation, it is essential that samples are homogenous and every laboratory receives a sample with the same water content.

We tested two methods:

1. Starting with a dry soil from the Wepal stock. These soils are homogeneous and already distributed in pots $(100 \mathrm{~g} / \mathrm{pot})$. Every participants should receive a comparable sample. Water had to be added in a known amount and should be homogeneous present in the pot content.

2. Selecting bulk amount of sample from the field or from the outside store of WEPAL and homogenise, followed by distribution in pots. If necessary, the sample should be air dried to a water content that enables sieving over $2 \mathrm{~mm}$ or to the desired water content.

Using method 1, we could guarantee that all laboratories receive the same soil sample. However, during wetting lumps of soil were formed, wet at the outside and dry inside, especially when clay was used. Extra grinding at Wepal or by the participant would thus be necessary. During grinding unpredictable evaporation will occur, resulting in an unknown water content and a high uncertainty. Consequently, it cannot be guaranteed that the water content in each sample within a series of a specific distributed soil is identical.

In method 2, we selected wet bulk soils below field capacity. Criteria were:

1. No big lumps, and possible to use a sieve of $2 \mathrm{~mm}$;

2. Different water contents in the sample.

We selected two sandy soils and one clay soil. Water contents varies between 0 and $20 \%$ based on the wet sample (Table 1 ).

$20 \mathrm{~kg}$ of soil was sieved over a $2 \mathrm{~mm}$ sieve (Photo 1 ), followed by mixing in a concrete mill (photo 2). In the mill, we used an insert suitable for $20 \mathrm{~kg}$ (photo 3 ) of material. During turning of the mill, pots 
were filled with approx. $160 \mathrm{~g}$ of soil. The pots were closed airtight. In total 30 pots were filled. The samples were stored at $4{ }^{\circ} \mathrm{C}$ until distribution. A small experiment has shown that storing at room temperature in sunlight did not cause reduction of weight of the pot during 1 months and not even after 12 months.

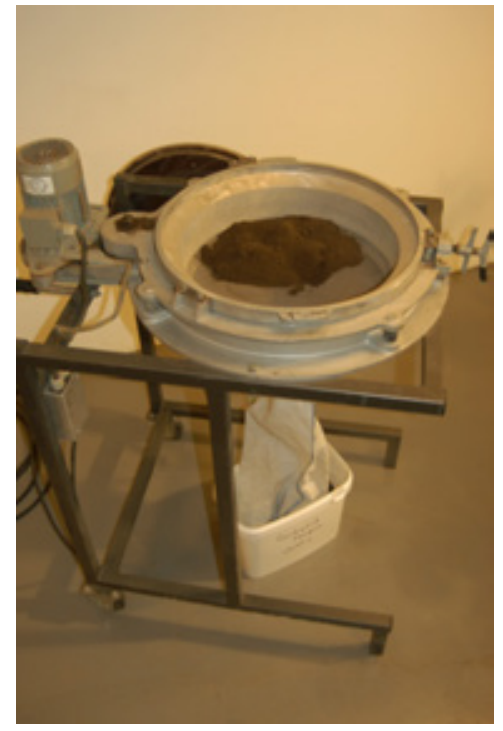

Photo 1 Sieving equipment

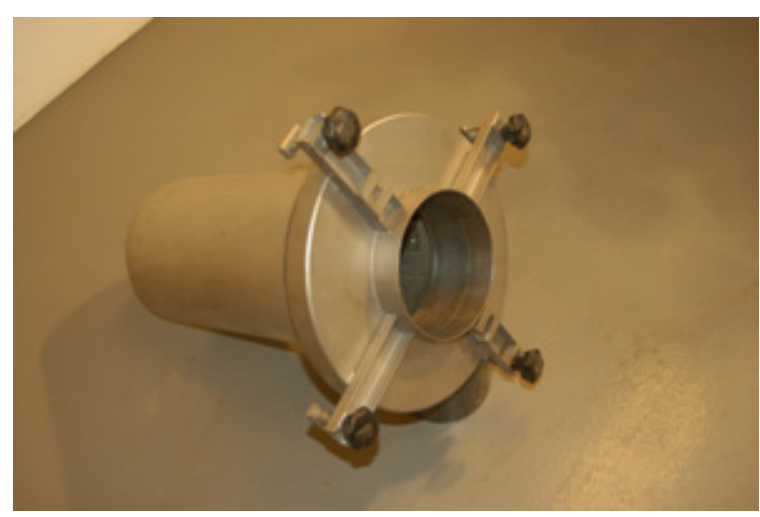

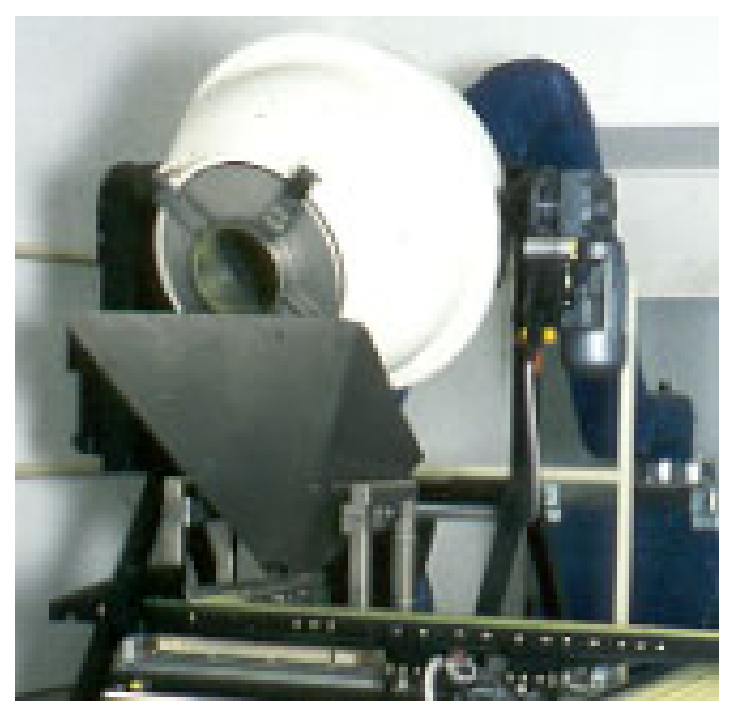

Photo 2 Concrete mill

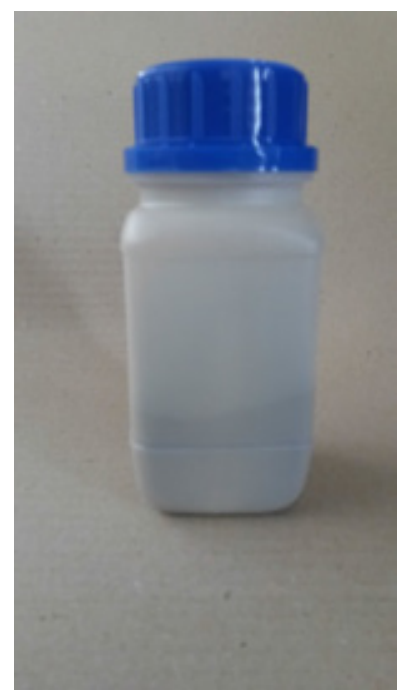

Photo 4 Pot with soil sample, ready for

distribution
Photo 3 Insert for concrete mill 
The four soil samples selected had different soil properties (Table 1) and water contents (according ISO 11465:1993). The participants were not informed about the water contents in the samples. The first three lines in Table 1 give values based on dry matter, which is the standard way of reporting water content in soil sciences. In ISO/DIS 20244, soil water content is reported based on the wet sample, which is convenient for measurements made in the field. This water content is presented in the last line of Table 1.

Table 1 Values of general soil parameters in the analysed soils

\begin{tabular}{|c|c|c|c|c|}
\hline Parameter & 1 & 2 & 3 & 4 \\
\hline Clay (\%) dry matter & 8 & 27 & 2 & 27 \\
\hline Clay $(\%)$ based on wet sample* & 7 & 20 & 2 & 22 \\
\hline Organic matter $(\%)$ based on wet sample & 3.0 & 8.6 & 1.4 & 9.2 \\
\hline Water (\%) dry matter & 13.2 & 23.3 & 5.9 & 17.5 \\
\hline
\end{tabular}

The samples were stored at $4^{\circ} \mathrm{C}$ until distribution. The samples were distributed during the first week of November 2016.

To monitor the homogeneity and stability of the test materials, a number of pots were selected to analyse the water content. ISO 11465:1993 was applied for these analyses.

\subsection{Measurement of water content}

The participants carried out the measurement according to ISO/DIS 20244. They were asked to perform the determination in four-fold. Participants submitted their results in an Excel-file supplied by WEPAL (see Annex 1).

In addition, the water content was determined according to ISO 11465:1993. The values were used to investigate the stability and homogeneity of the samples and to supply the 'real' value of the water content. ISO/DIS 20244 is designed as screening method to have a quick estimate of the water content. By comparing the results of the two methods, an estimate of the trueness is obtained.

\subsection{Statistical evaluation}

\subsubsection{ISO 5725 model}

Statistical testing for the validation was carried out according to the ISO 5725 Series. Outliers were identified using the Cochran's test and Grubbs' test described in ISO 5725-2. ISO 5725 assumes that only small differences exist in the intra laboratory variance between laboratories. Cochran's test, as described in ISO 5725-2, was used to test the validity of this assumption. Results with too large intra laboratory variance were identified as outliers and excluded from further evaluation.

Next Grubbs' test was applied to identify outliers with an extreme mean. 
After eliminating the outliers, the following parameters are calculated and reported:

$x \quad$ is the mean value, in \% based on wet sample;

$S_{\mathrm{r}} \quad$ is the repeatability standard deviation, in \% based on wet sample;

$V C_{r} \quad$ is the relative repeatability standard deviation, in percent;

$S_{\mathrm{R}} \quad$ is the reproducibility standard deviation, in \% based on wet sample;

$V C_{\mathrm{R}}$ is the relative reproducibility standard deviation, in percent.

\subsubsection{WEPAL model}

We used the WEPAL-model to calculate distribution curves of the results. The model calculates population characteristics (mean and standard deviation) from experimental datasets (Cofino 2000). It employs an estimate for the probability density function ( $p d f$ ) of the measurements and calculates a best fit based on all observed values. The implementation of the model used does not require uncertainty estimates for all data points. Instead, it relies on a Normal Distribution Approximation (NDA) for the pdf of the individual data points. In essence, the pdfs of the individual data points are superposed upon each other to create a continuous pdf that represents the entire distribution (all data points).

With the mathematical model, coefficients can be obtained by looking for the combination of data points that has the highest probability in the data set. This maximisation amounts to the identification of the first mode of the dataset. The coefficients can be used to calculate the weighted mean and standard deviation. Subsequent calculations give additional modes of the distribution.

For this validation, we have used the possibility to construct distribution curves using the data of the participants, which can have a role within the evaluation of the results. 


\section{Results and discussion}

\subsection{Stability and homogeneity of the samples}

\subsubsection{Homogeneity}

In the homogeneity test, we tested if a selection of four pots (out of 30 ) had the same water contents. We used the first pot filled, pot no 10, pot no 20 and pot no 30 and tested one day after preparation. The results are presented in Table 2.

Table 2 Results homogeneity test

\begin{tabular}{lccc} 
Sample & \multicolumn{3}{c}{ sandy soil (Nergena) (in \%) } \\
\cline { 2 - 4 } pot no. 1 & 11.76 & 11.67 & 11.72 \\
\hline pot no. 10 & 11.67 & 11.64 & 11.66 \\
\hline pot no. 20 & 11.68 & 11.61 & 11.65 \\
\hline pot no. 30 & 11.81 & 11.69 & 11.75 \\
\hline
\end{tabular}

\begin{tabular}{lccc} 
Sample & \multicolumn{3}{c}{ 2 Clay (floodplains) (in \%) } \\
\cline { 2 - 4 } & repl.1 & repl.2 & mean \\
\hline pot no. 1 & 19.03 & 18.94 & 18.99 \\
\hline pot no. 10 & 18.77 & 18.87 & 18.82 \\
\hline pot no. 20 & 18.95 & 18.91 & 18.93 \\
\hline pot no. 30 & 18.88 & 18.88 & 18.88 \\
\hline
\end{tabular}

\begin{tabular}{lccc} 
Sample & \multicolumn{3}{c}{ 3 Sandy soil (in \%) } \\
\cline { 2 - 4 } pot no. 1 & repl.1 & repl.2 & mean \\
\hline pot no. 10 & 5.68 & 5.70 & 5.69 \\
\hline pot no. 20 & 5.54 & 5.49 & 5.52 \\
\hline pot no. 30 & 5.64 & 5.65 & 5.65 \\
\hline
\end{tabular}

\begin{tabular}{lccc} 
Sample & \multicolumn{3}{c}{ 4 Clay (floodplains) (in \%) } \\
\cline { 2 - 4 } & repl.1 & repl.2 & mean \\
\hline pot no. 1 & 14.90 & 14.88 & 14.89 \\
\hline pot no. 10 & 14.87 & 14.76 & 14.82 \\
\hline pot no. 20 & 14.88 & 14.89 & 14.89 \\
\hline pot no. 30 & 14.99 & 14.91 & 14.95
\end{tabular}

We used our statistical test (based on ISO 13528) for homogeneity. The results are presented in Table 3. In our test, we assume a relative standard deviation of $1.5 \%$ in the interlaboratory trial. This is very strict for this analysis on water content. ISO 11465 mentioned $1.5 \%$ for the accepted difference in a duplicate analysis. To be suitable as a sample that can be distributed, the standard deviation should be smaller. In our test we use a factor of $3.3,<0.3$ in last column. Only for the lowest water content (sample 3), our standard criterion is not achieved. For the purpose of this validation, we think that the sample is still suitable, because the standard variation of the screening test will be much higher than the $1.5 \%$ used in our procedure. 
Table 3 Evaluation of homogeneity test

\section{Sample 1 Sandy Soil (Nergena)}

mean concentration

$11.69 \%$

s.d.

$0.06 \%$

r.s.d.

$0.6 \%$

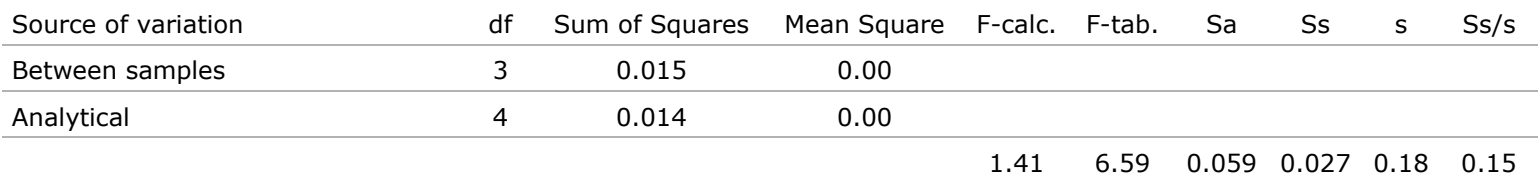

\section{Sample 2 Clay (floodplains) water content high}

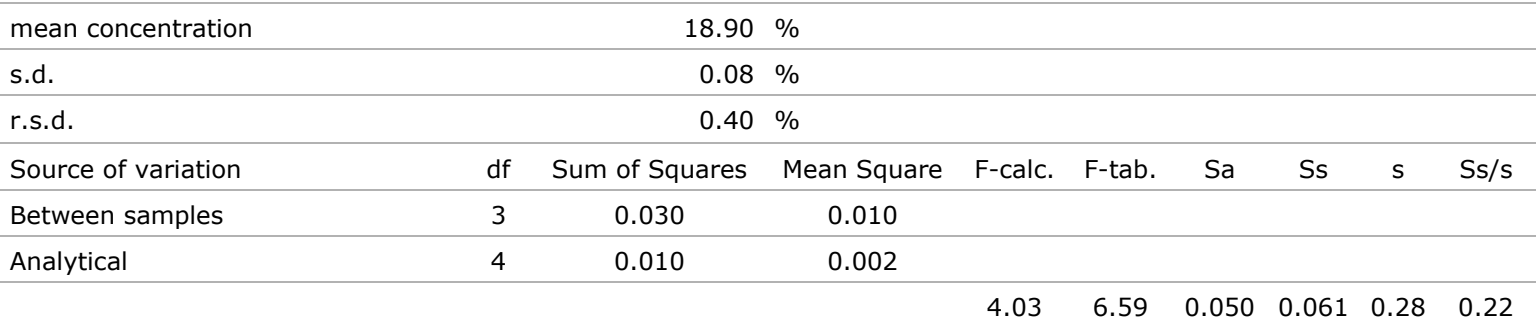

\section{Sample 3 Sandy Soil}

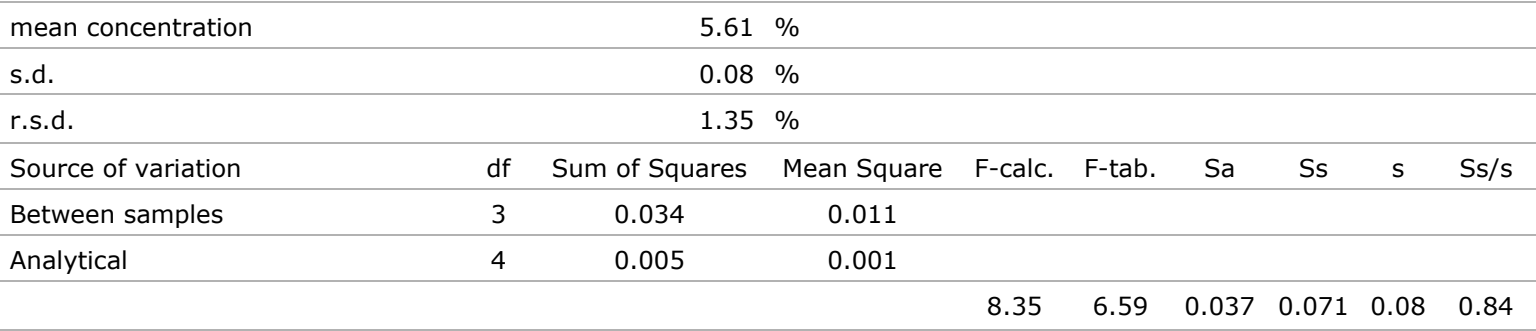

\section{Sample 4 Clay (floodplains) water content low}

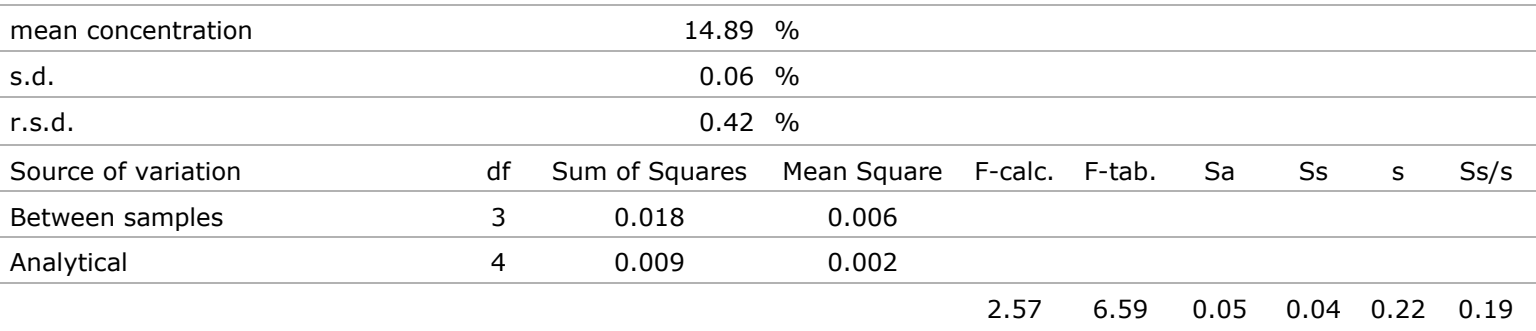

\subsubsection{Stability of the stored samples}

During preparation of the samples, we observed that the sandy soils were sensitive for further drying. We therefore tested if after the sample preparation the water content remains constant and repeated the water content measurement in time $s$ as presented in Table 4. Only a small decrease in water content occurs in time. This decrease is very small compared to the inaccuracy of the results in the method and can therefore be ignored. 
Table 4 Stability of the water content during storage. Water content in $\% .(x)=$ standard deviation

\begin{tabular}{lcrr} 
Sample & start & 4 months & 9 months \\
Sandy soil 1 & $11.72(0.06)$ & & $11.63(0.07)$ \\
\hline Clay 1 & $18.90(0.06)$ & $18.64(0.02)$ & $18.64(0.10)$ \\
\hline Sandy soil 2 & $5.62(0.07)$ & $5.58(0.02)$ & $5.54(0,04)$ \\
\hline Clay 2 & $14.89(0.06)$ & & $14.73(0.11)$ \\
\hline
\end{tabular}

For the purpose of the validation, it can be concluded that the bottles used for the validation are fit for purpose. The samples were distributed 8 months after preparation.

\subsubsection{Stability of sample after opening of the bottle}

For first opening of the bottle, the securing of the closure has to be destroyed. We investigated the stability of the water content after opening of the bottle and closing again. We took samples not only directly after opening, but also after 1,5 and 7 days. Results are presented in Table 5. A small decrease is present for the water content, combined with a small increase for the standard deviation. These are however small compared to the inaccuracy of the method to be validated. The samples are sufficient stable to take another sample within 7 days after opening of the bottle.

Table 5 Stability of water content after opening and closure of the bottle. Water content in \%, $(x)=$ standard deviation

\begin{tabular}{lccc} 
Sample & start & 24 hrs & 5 days \\
Sandy soil 1 & $11.72(0.06)$ & $11.58(0.07)$ \\
\hline Clay 1 & $18.90(0.06)$ & $18.84(0.02)$ & \\
\hline Sandy soil 2 & $5.62(0.07)$ & $5.64(0.12)$ & $5.50(0.24)$ \\
\hline Clay 2 & $14.89(0.06)$ & & \\
\hline
\end{tabular}

\subsection{Conclusions for the samples prepared}

- The water content in the four soils used is homogeneous distributed in the sub-samples and for each of the four soils the water content in the first pot is the same as in the last pot.

- During storage, there was a small change in water content. The highest observed change was in the clay sample with the highest water content during the first 4 months of storage. There was a slight increase in the standard deviation. The samples were distributed after 8 months. The observed changes for each of the four samples are small and assumed negligible compared with the deviations expected in this screening method.

- Repeating the soil analysis from the same pot is possible for at least a week under the condition that the pots are closed in-between the analysis. The participants received instructions to minimize evaporation caused by the opening period of the pots during sampling. 


\subsection{Experiences of the laboratories}

Eleven Laboratories contributed to this validation trial.

Two of the laboratories provided comments together with their results:

- Two laboratories had difficulties with filtration of sample 1 and 3 . It was necessary to centrifuge these samples before filtration;

- Using the same mass of soil and sucrose solution (e.g. $20 \mathrm{~g}$ ) provides a sample that can be filtrated.

- The standard method is not clear about the procedure of mixing the soil with the sucrose solution (paragraph 7.4c). Shaking is normally used instead of stirring.

Photo 5, supplied by one of the participants, showed that turbid samples were obtained. This participant also mentioned that turbidity and colour had no effect on the result because the measurement is based on reflection. A "full" filtration is therefore not necessary.

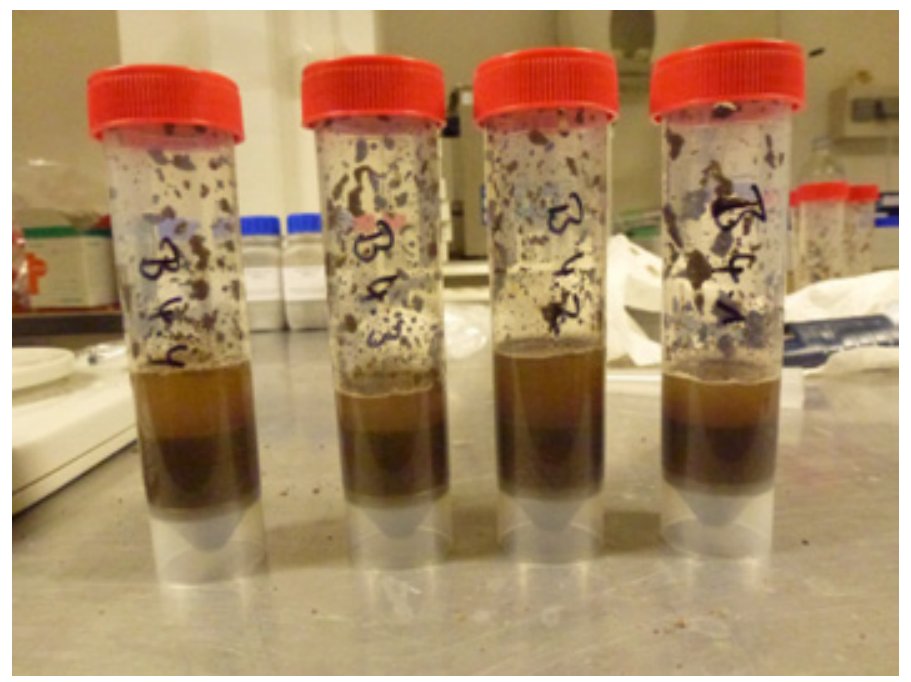

Photo 5 Obtained solutions of one of the participants

Two laboratories did not make a calibration curve as described in the standard method. Instead of adding water to the same amount of sucrose solution, they prepared solutions with a known percentage of water. This was well documented in the excel-file. Furthermore, they used different ratios soil - sucrose solutions for the replicates. Consequently:

- This other calibration requires another method of calculation, the two laboratories reported wrong values for the water contents;

- The calibration curve was not chosen in the relevant range, all measured values were between the first and second point of the standard curve;

- Furthermore, the calibration curve was fitted using a straight line instead of a quadratic function. In the used part of the curve, rather big differences are obtained when the wrong function is used. Even with a quadratic function the fit though the points in the used range is questionable;

- Because of the different ratio's soil - sucrose solution together with the use of the wrong function for the calibration curve a high standard deviation in the samples was obtained.

We recalculated the results and communicated it with the laboratories concerned. Because two laboratories that did not follow the intended procedure that resulted in erroneous results, it is recommended that the text in the method on how to obtain the calibration curve has to be revised.

Most of the laboratories (7) used $15 \mathrm{~g}$ of soil sample and $15 \mathrm{~g}$ of sucrose solution (ratio 1 to 1 ). One laboratory used a ratio of 1 to 2 ( $85 \mathrm{~g}$ soil and $170 \mathrm{~g}$ sucrose solution). Two laboratories used variable ratios $(1: 1,1: 1.5$ and $1: 2)$. Three laboratories prepared a standard series, which was not in a relevant range, resulting in values between the first and second point of the calibration curve. 


\subsection{Statistical evaluation according ISO 5725}

Individual results of the laboratories are presented in Annex 2.

Table 6 presents the results of the participating laboratories after evaluation according ISO 5725.

Table 6 Results of validation of ISO/DIS 20244.

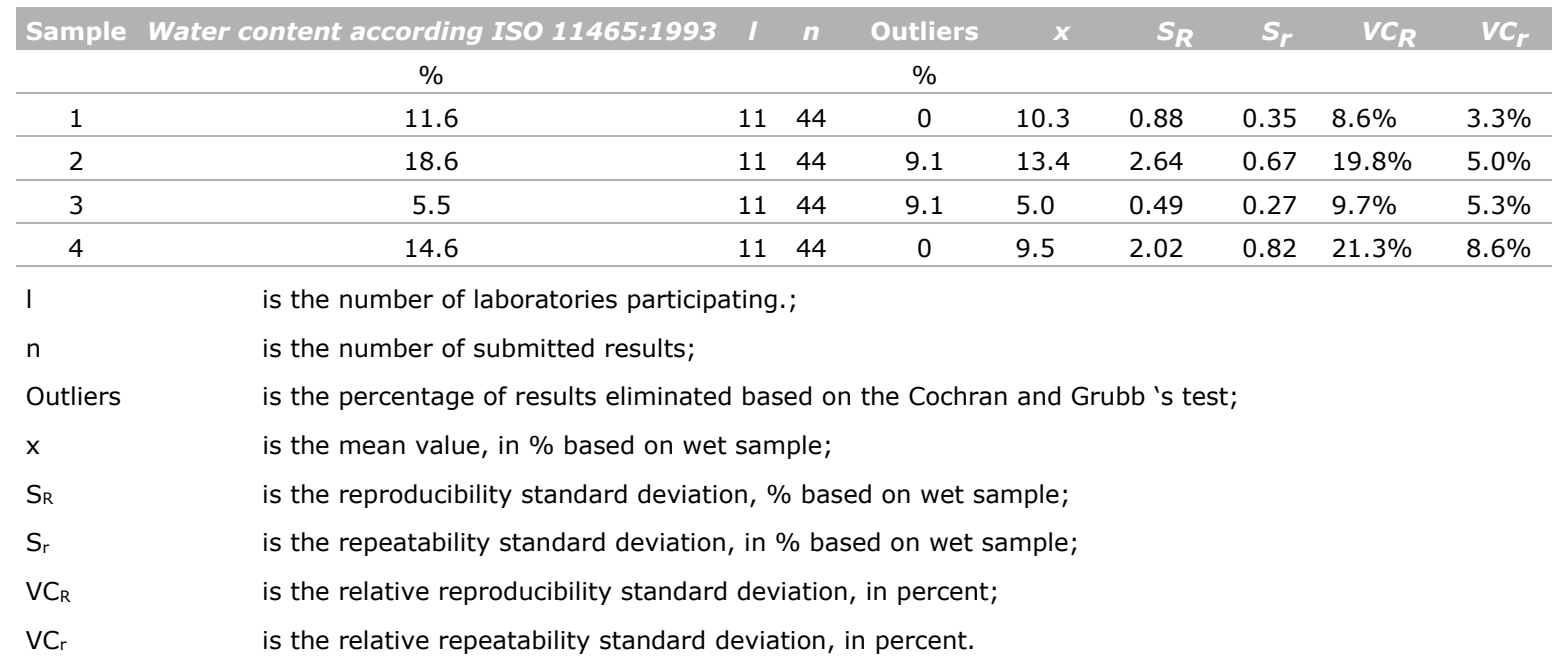

In Annex 2 the outliers eliminated from the calculations are indicated with $* *$, stragglers marked with * are included in the calculations.

\section{$3.5 \quad$ Trueness}

ISO 20244 is a screening method for a fast measurement of the water content is soil. This water content is normally measured using ISO 11465:1993 in which the mass reduction after heating at $105^{\circ} \mathrm{C}$ is measured. By comparing the results of the two methods, the trueness of the screening method ISO/DIS 20244 can be established. In Figure 1, the two methods are compared.

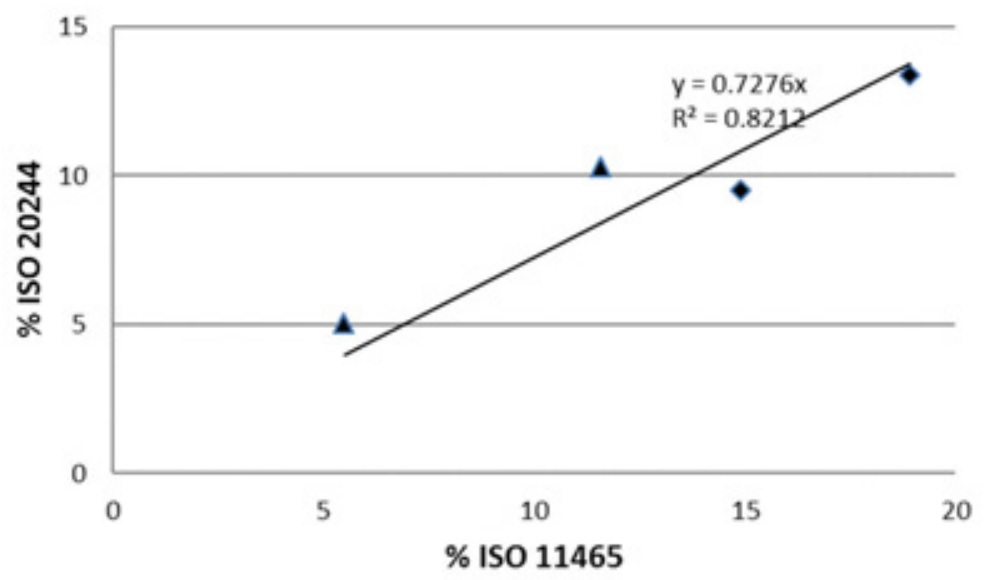

Figure 1 Comparison of water content according ISO 20244 and ISO 11465.

triangle $=$ sand: rhombus $=$ clay 
Assuming a linear relation going through the origin, ISO 20244 gives results that are too low (slope is 0.73 instead of 1). Looking in more detail, in both clay samples the water content measured and expressed as percentage water is $5.5 \%$ too low, suggesting a constant systematic error. A line through the origin with a slope of 0.87 can fit the results of the two sand samples. The results of ISO/DIS 20244 are closer to the values measured with ISO11465 but relatively $13 \%$ too low.

\subsection{Effect of soil properties}

It seems that the new standard is able to extract only a part of the water. Not all the water in soil is freely available. Water can be bound to minerals, micro pores in soil aggregates and organic matter. It is possible that the sucrose solution is not able to extract the strongly bound water. Using the drying method (ISO 11465), this water will evaporate at $105^{\circ} \mathrm{C}$ and consequently be measured. Figure 2A shows that the differences between ISO 11465 and ISO 20244 (results expressed as \% water) can be explained by the clay content. Because the clay content and the organic matter content (loss of ignition) in the used samples are correlated, the difference can also be explained by organic matter alone (Figure 2B).
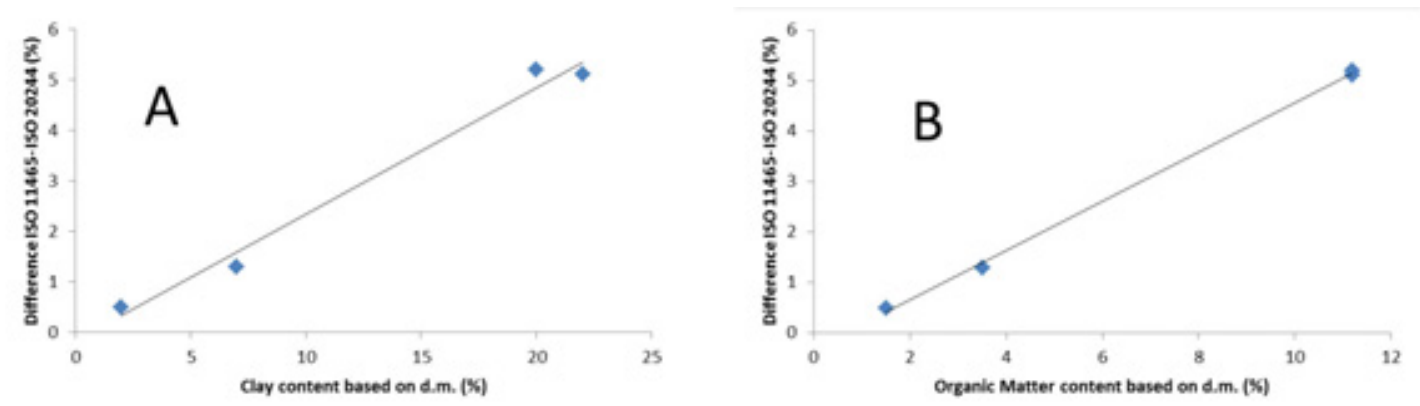

Figure 2 Difference in water content (\% water) measured according ISO 11465 and ISO 20244 (result ISO 11465 - ISO/DIS 20244) as function of: A clay content and B organic matter content

The influence of the clay-content on the results was not observed during method development (see Annex A of ISO/DIS 20244). This can be explained as follows. The distributed samples originated from the field and the water phase was in equilibrium with the solid phase. Part of the water was strongly bound to the soil matrix. The method is developed using dry samples followed by addition of water and immediately measurement of the water content. It is assumed that the water in these samples was not in equilibrium with the solid phase. This may explain the difference between the lower results in this report compared to the results in Annex A of the standard (full recovery of the added water).

Regarding the correlations in Figure 2, it is advised to investigate a large number of samples with the two methods. Doing this it may be possible to develop a correction factor based on clay and or organic matter content.

\subsection{Statistical evaluation according the WEPAL model.}

Using graphical results of the WEPAL-model, it becomes clear if there is a normal distribution of the reported results and if a specific group of laboratories is responsible for a deviation from the normal distribution. The distribution curves and ranked overviews of the results are presented in Figure 3.

These left graphs in Figure 3 show the submitted results have a skewed distribution in sample 2, 3 and 4 respectively two, three and two results are not included within the normal distribution around the calculated NDA-mean value and strongly deviate from this calculated mean. Using the WEPAL- 
model the NDA-mean in sample 2 and 4 is slightly higher than the mean value reported in Table 6 , but is not the same as measured using ISO 11465:1993 (Table 7)

Table 7 Comparison between mean (ISO 11465) Mean of validation and NDA mean (WEPAL method)

\begin{tabular}{cccc} 
Sample & Water content according ISO $11465: 1993$ & $\begin{array}{c}\text { Mean value } \\
\text { (Table 6) }\end{array}$ & $\begin{array}{c}\text { Mean value WEPAL model } \\
\text { \% }\end{array}$ \\
\hline 1 & 11.6 & 10.3 & 10.3 \\
\hline 2 & 18.9 & 13.4 & 14.6 \\
\hline 3 & 5.5 & 5.0 & 4.9 \\
\hline 4 & 14.9 & 9.5 & 10.1 \\
\hline
\end{tabular}




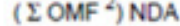

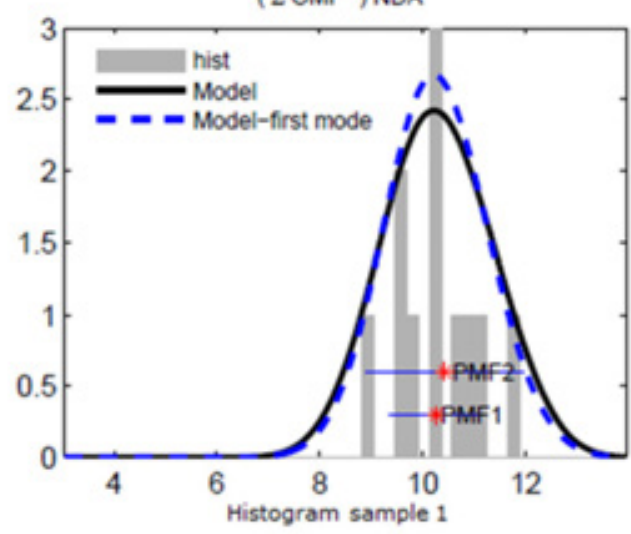

$\left(\Sigma \mathrm{OMF}^{\wedge}\right) \mathrm{NDA}$

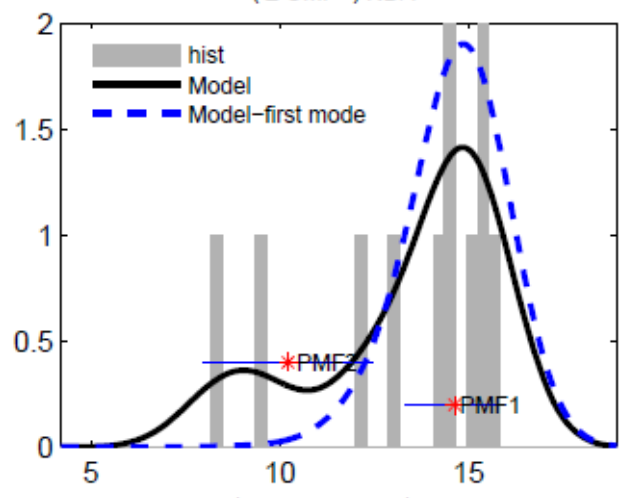

Histogram Sample 2

$\left(\Sigma \mathrm{OMF}^{4}\right)$ NDA

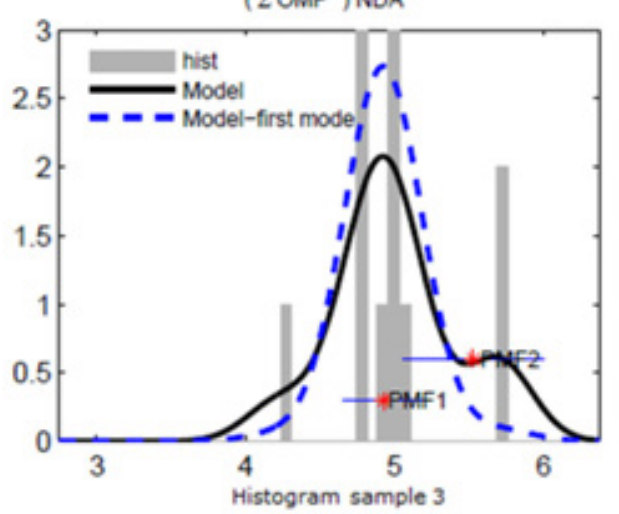

( OMF $\left.^{4}\right)$ NDA

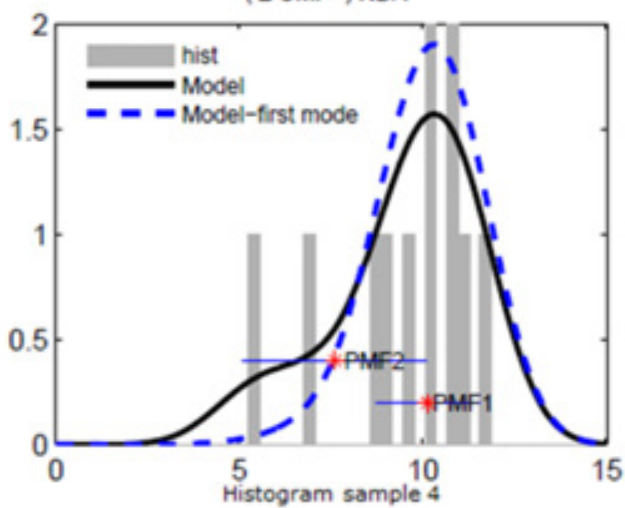

Ranked Overview - Sample 1 Moisture Content

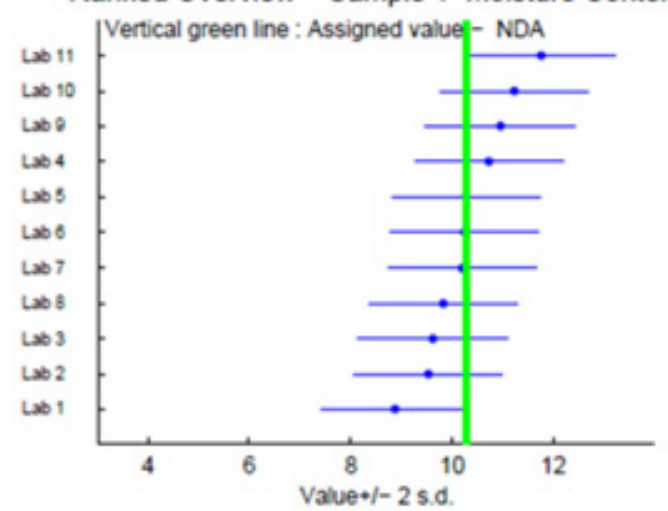

Ranked Overview - Sample 2 Moisture Content

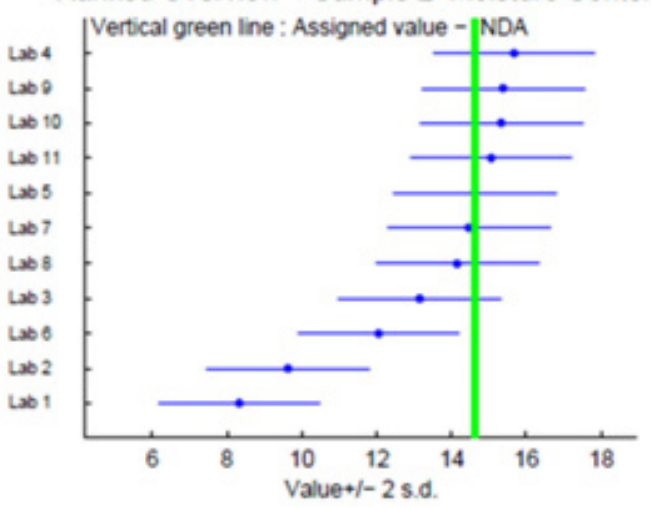

Ranked Overview - Sample 3 Moisture Content

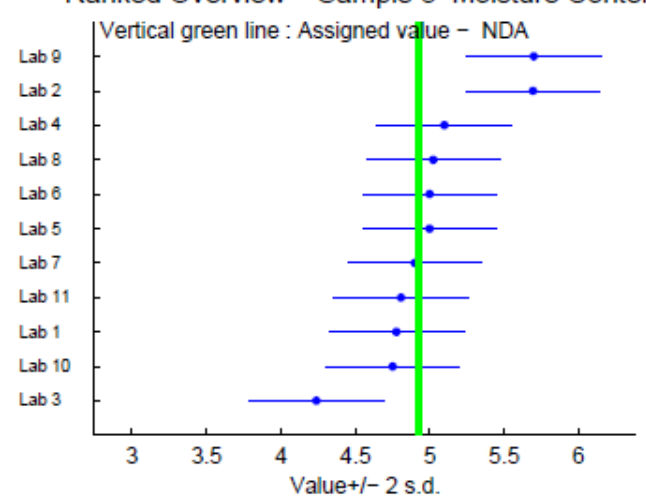

Ranked Overview - Sample 4 Moisture Content

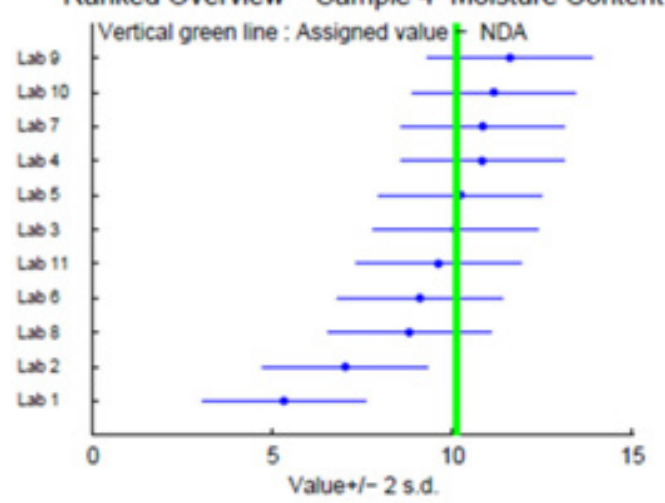

Figure 3 Distribution curves and ranked overview of the results for the four analysed samples 


\section{Discussion and recommendations}

This report presents the validation of ISO/DIS 20244. It was first investigated how the samples had to be prepared in order to obtain a set of samples having the same water content. During storage, the water content was not allowed to change. It is shown in this report that samples were prepared fulfilling these criteria.

In the validation study, 11 laboratories have analysed four different samples in four fold. The results are evaluated according ISO 5725 and the results are given in this report (Annex 2 and Table 6). It is the role of the responsible ISO working group to decide if the repeatability and reproducibility are sufficient for this screening technique.

Because ISO/DIS 20244 is a screening method designed to give a quick estimate of the water content, which is normally measured using the more time consuming method ISO 11465, it was also possible to measure the trueness of the results. It is shown that ISO/DIS 20422 gives lower results than ISO 11465. Taken into account the results of all samples, the results are relatively $27 \%$ too low. If only the two sand samples are considered, the results are better comparable, but still $13 \%$ too low. The two clay samples were of the same origin but having different water content. Results of the clay samples were absolutely $5.5 \%$ too low (13.4 and $9.5 \%$ instead of 18.9 and $14.9 \%$ ). It can be concluded that the sucrose solution is not able to extract the same amount of water as is removed with drying the samples at $105^{\circ} \mathrm{C}$.

The difference between ISO 11465 and ISO 20244 correlates with both clay content and organic matter content. It is recommended to investigate this more intensively with a large number of samples. Such a study may yield a correction factor based on the general soil properties clay and organic matter content.

The ISO working group responsible for this standard has to decide what should be done with the results presented in this report and which further actions are necessary. 


\section{References}

Cofino, W.P., I. van Stokkum, D.E. Wells, R.A.L. Peerboom, F. Ariese (2000). A new model for the inference of population characteristics from experimental data using uncertainties. Application to interlaboratory studies. Chemom. Intell. Lab. Syst. 53, 37-55.

Cofino, W.P., Molenaar, J. and Torfs, P. Evaluating Proficiency tests with Robust Statistics. Wiley StatsRef: Statistics Reference Online. In press.

ISO 5725-2:1994 - accuracy (trueness and precision) of measurement methods and results - Part 2: Basic method for the determination of repeatability and reproducibility of a standard measurement method.

ISO 11465:2005 - Soil Quality - Determination of dry matter and water content on a mass basis Gravimetric method.

ISO 13528:2015 (Cor. 2016-10) - Statistical methods for use in proficiency testing by interlaboratory comparisons. 


\section{Annex 1 Excel sheet used by the participants to deliver the results}

The excel sheet presented is delivered by one of the participants

Walidation Interlaboratory Trial for ISO/CD 20244 Soil quality - An on-site test method to quickly determine water contents in soil by refractometry

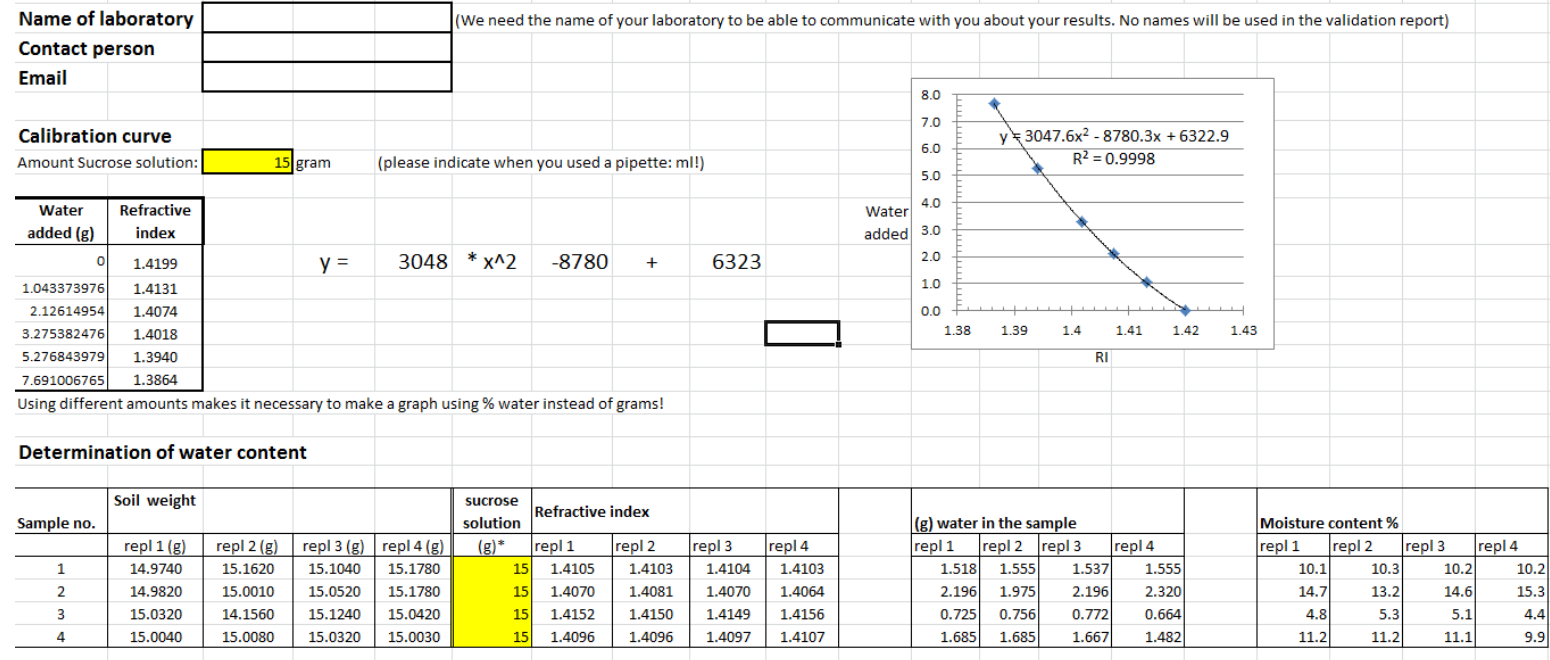

* please indicate when you used a pipette $(\mathrm{ml})$

Please send these results to WEPAL before 16th December 2016 using our email address: results.wepal@wur.nl 


\section{Annex 2 Results of individual laboratories}

\begin{tabular}{|c|c|c|c|c|c|c|}
\hline Lab number & Repl.1 & Repl.2 & Repl.3 & Repl.4 & average & stdev \\
\hline \multicolumn{7}{|l|}{ Sample 1} \\
\hline 1 & 9.34 & 7.95 & 9.13 & 9.08 & 8.88 & 0.627 \\
\hline 2 & 9.83 & 9.72 & 8.90 & 9.68 & 9.53 & 0.426 \\
\hline 3 & 9.72 & 9.67 & 9.55 & 9.55 & 9.62 & 0.086 \\
\hline 4 & 10.80 & 10.70 & 10.80 & 10.60 & 10.73 & 0.096 \\
\hline 5 & 10.40 & 10.40 & 10.30 & 10.00 & 10.28 & 0.189 \\
\hline 6 & 10.80 & 10.20 & 10.10 & 9.90 & 10.25 & 0.387 \\
\hline 7 & 10.10 & 10.30 & 10.20 & 10.20 & 10.20 & 0.082 \\
\hline 8 & 10.70 & 9.50 & 9.50 & 9.60 & 9.83 & 0.585 \\
\hline 9 & 11.30 & 10.70 & 11.10 & 10.70 & 10.95 & 0.300 \\
\hline 10 & 11.00 & 11.30 & 11.30 & 11.30 & 11.23 & 0.150 \\
\hline 11 & 12.03 & 11.64 & 11.91 & 11.45 & 11.76 & 0.262 \\
\hline Lab number & Repl.1 & Repl.2 & Repl.3 & Repl.4 & average & stdev \\
\hline \multicolumn{7}{|l|}{ Sample 2} \\
\hline 1 & 8.87 & 8.95 & 7.69 & 7.79 & $8.33 *$ & 0.678 \\
\hline 2 & 11.44 & 8.81 & 8.63 & 9.65 & $9.63 *$ & 1.284 \\
\hline 3 & 13.20 & 13.20 & 13.10 & 13.10 & 13.15 & 0.058 \\
\hline 4 & 15.70 & 15.60 & 15.70 & 15.70 & 15.68 & 0.050 \\
\hline 5 & 13.50 & 15.10 & 15.00 & 14.90 & 14.63 & 0.754 \\
\hline 6 & 11.20 & 12.30 & 12.60 & 12.10 & 12.05 & 0.603 \\
\hline 7 & 14.70 & 13.20 & 14.60 & 15.30 & 14.45 & 0.889 \\
\hline 8 & 14.30 & 12.20 & 16.50 & 13.60 & 14.15 & $1.794 * *$ \\
\hline 9 & 15.40 & 14.80 & 15.70 & 15.60 & 15.38 & 0.403 \\
\hline 10 & 16.00 & 15.30 & 15.30 & 14.70 & 15.33 & 0.532 \\
\hline 11 & 15.35 & 14.45 & 14.99 & 15.43 & 15.05 & 0.444 \\
\hline
\end{tabular}

* Straggler (Grubb's test) results included in the calculations

** Outlier (Cochran test) All four results are excluded from calculations 


\begin{tabular}{|c|c|c|c|c|c|c|}
\hline Lab number & Repl.1 & Repl.2 & Repl.3 & Repl.4 & average & stdev \\
\hline \multicolumn{7}{|l|}{ Sample 3} \\
\hline 1 & 4.74 & 4.64 & 3.51 & 6.22 & 4.78 & $1.112^{* *}$ \\
\hline 3 & 4.20 & 4.28 & 4.27 & 4.20 & 4.24 & 0.043 \\
\hline 4 & 5.40 & 4.60 & 5.40 & 5.00 & 5.10 & 0.383 \\
\hline 6 & 5.40 & 5.00 & 4.90 & 4.70 & 5.00 & 0.294 \\
\hline 7 & 4.80 & 5.30 & 5.10 & 4.40 & 4.90 & 0.392 \\
\hline 8 & 5.00 & 5.00 & 5.00 & 5.10 & 5.03 & 0.050 \\
\hline 9 & 5.50 & 5.60 & 5.90 & 5.80 & 5.70 & 0.183 \\
\hline
\end{tabular}

** Outlier (Cochran test) All four results are excluded from calculations

\begin{tabular}{|c|c|c|c|c|c|c|}
\hline Lab number & Repl.1 & Repl.2 & Repl.3 & Repl.4 & average & stdev \\
\hline \multicolumn{7}{|l|}{ Sample 4} \\
\hline 1 & 5.37 & 4.84 & 5.93 & 5.12 & $5.32 *$ & 0.464 \\
\hline 3 & 10.10 & 10.10 & 10.10 & 10.00 & 10.08 & 0.050 \\
\hline 4 & 11.00 & 10.70 & 11.10 & 10.50 & 10.83 & 0.275 \\
\hline 6 & 7.60 & 10.70 & 9.60 & 8.50 & 9.10 & 1.344 \\
\hline 7 & 11.20 & 11.20 & 11.10 & 9.90 & 10.85 & 0.635 \\
\hline 8 & 7.80 & 8.70 & 7.80 & 10.90 & 8.80 & 1.463 \\
\hline 9 & 11.60 & 11.60 & 11.60 & 11.60 & 11.60 & 0.000 \\
\hline
\end{tabular}

* Straggler (Grubb's test) results included in the calculations 
Wageningen Environmental Research P.O. Box 47

6700 AA Wageningen

The Netherlands

T +31 (0)317480700

www.wur.nl/environmental-research

Wageningen Environmental Research Report 2911

ISSN 1566-7197
The mission of Wageningen University \& Research is "To explore the potential of nature to improve the quality of life". Under the banner Wageningen University \& Research, Wageningen University and the specialised research institutes of the Wageningen Research Foundation have joined forces in contributing to finding solutions to important questions in the domain of healthy food and living environment. With its roughly 30 branches, 5,000 employees and 10,000 students, Wageningen University \& Research is one of the leading organisations in its domain. The unique Wageningen approach lies in its integrated approach to issues and the collaboration between different disciplines.

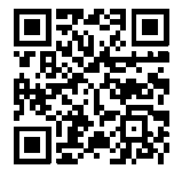





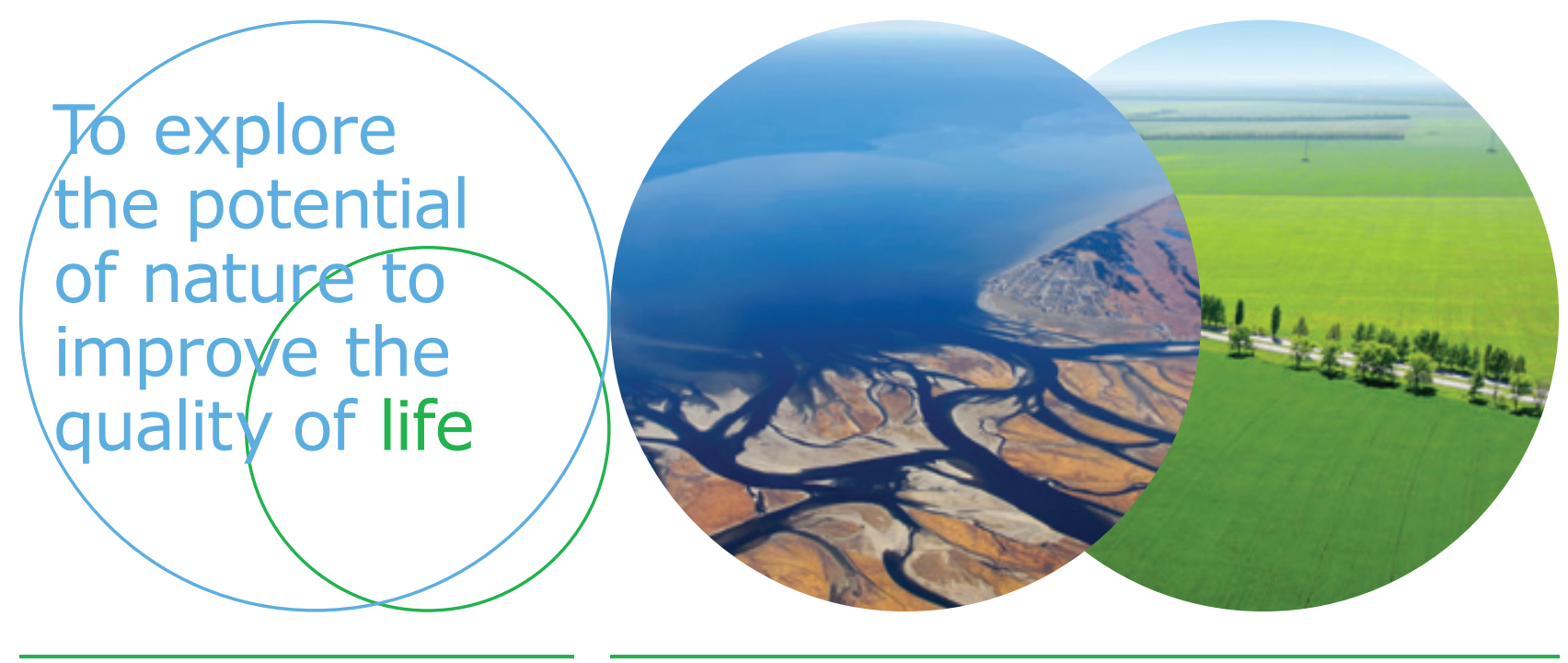

Wageningen Environmental Research P.O. Box 47

$6700 \mathrm{AB}$ Wageningen

The Netherlands

$\mathrm{T}+31(0) 317480700$

www.wur.eu/environmental-research

Report 2911

ISSN 1566-7197
The mission of Wageningen University \& Research is "To explore the potential of nature to improve the quality of life". Under the banner Wageningen University \& Research, Wageningen University and the specialised research institutes of the Wageningen Research Foundation have joined forces in contributing to inding solutions to important questions in the domain of healthy food and living environment. With its roughly 30 branches, 5,000 employees and 10,000 students, Wageningen University \& Research is one of the leading organisations in its domain. The unique Wageningen approach lies in its integrated approach to issues and the collaboration between different disciplines. 